MRS Advances (C) 2018 Materials Research Society. This is an Open Access article, distributed under the terms of the Creative Commons Attribution licence (http://creativecommons.org/licenses/by/4.0/), which permits unrestricted re-use, distribution, and reproduction in any medium, provided the original work is properly cited.

DOI: 10.1557/adv.2018.239

\title{
A critical role of hydrogen sulfide evolution during MOCVD of single phase thin film tin sulfide using ditertiarybutylsulfide as a less toxic precursor
}

\author{
Andrew J. Clayton ${ }^{1}$, Cecile M. E. Charbonneau ${ }^{2}$, Peter J. Siderfin ${ }^{1}$ and Stuart J. C. Irvine ${ }^{1}$ \\ ${ }^{1}$ Centre for Solar Energy Research, College of Engineering, Swansea University, OpTIC, Ffordd William \\ Morgan, St. Asaph Business Park, St. Asaph, Denbighshire, LL17 0JD, UK
}

${ }^{2}$ Ser Solar, College of Engineering, Swansea University, Bay Campus, Crymlyn Burrows, Fabian Way, Swansea, West Glamorgan, SAI $8 E N$, UK

ABSTRACT

Thin film tin sulphide (SnS) was deposited on to molybdenum (Mo) substrates using metal organic chemical vapor deposition at $470^{\circ} \mathrm{C}$ using tetraethyltin and ditertiarybutylsulfide as precursors. In situ mass spectroscopy was used to study the exhaust gas species downstream of the reaction zone. The precursor vapor carrier gas was either nitrogen or hydrogen, thin film SnS only forming when the latter was used. Mass spectroscopy determined that hydrogen sulfide was being produced and playing a critical role in the vapor phase reaction process and adsorption of tin and sulfur on to the Mo surface. As-grown grain sizes were determined by scanning electron microscopy and were observed to be large averaging around 2 microns across. X-ray diffraction showed the films to be single phase SnS without any parasitic $\mathrm{Sn}_{2} \mathrm{~S}_{3}$ or $\mathrm{SnS}_{2}$ phases, with a small amount of $\mathrm{MoS}_{2}$ also being detected.

\section{INTRODUCTION}

Thin film tin sulfide ( $\mathrm{SnS})$ is an attractive material for solar absorption in photovoltaics due to its high absorption coefficient at visible wavelengths [1]. Its earth abundant non-toxic constituents give potential for high throughput module production, which is an important consideration as energy demands increase and materials availability of existing technologies, such as cadmium telluride (CdTe) and copper indium gallium diselenide (CIGS) become uncertain [2]. To date, progress in conversion efficiencies for $\mathrm{SnS}$ solar cells has been slow, with a certified world record of $4.4 \%$ [3]. This is very short of the theoretical conversion efficiency limit of $32 \%$ [4]. The challenges with using $\mathrm{SnS}$ as a thin film solar cell absorber have mainly been associated to its small grains and poor band alignment with p-n junction counter-parts [3]. This leads to heavy recombination within the bulk material due to grain boundaries acting as recombination centres and poor energy matches to n-type buffers creating losses at the junction.

There are many reports focusing on the appropriate n-type buffer material to create small conduction band offsets with $\mathrm{SnS}$, which has a low electron 
affinity [5]. Post-growth annealing steps are generally carried out to enlarge the SnS grains and reduce grain boundary defect concentration [3]. This is typically carried out in a sulfur atmosphere to reduce sulfur loss from the annealed film. Hydrogen sulphide $\left(\mathrm{H}_{2} \mathrm{~S}\right)$ has been shown [3] to be a successful sulfur precursor, also assisting in grain enlargement during post-growth annealing. Unfortunately, $\mathrm{H}_{2} \mathrm{~S}$ is a highly toxic gas so special measures are required for its use [6]. Ditertiarybutylsulfide $\left(\mathrm{t}-\mathrm{Bu}_{2} \mathrm{~S}\right)$ is an alternative sulfur source, with less toxicity than $\mathrm{H}_{2} \mathrm{~S}$ and has been used by the authors employing the metal organic chemical vapor deposition (MOCVD) process [7]. Tetraethyltin $\left(\mathrm{Et}_{4} \mathrm{Sn}\right)$ was used in this study as the tin precursor with successful growth of single phase SnS on to molybdenum (Mo) substrates. Post-growth annealing was not necessary with high growth temperatures of $470^{\circ} \mathrm{C}$ facilitating large grain growth. In situ mass spectroscopy was used to give insight into the reaction process.

\section{EXPERIMENT}

The MOCVD process used either nitrogen or hydrogen as carry gas to transport the $\mathrm{Et}_{4} \mathrm{Sn}$ and $\mathrm{t}-\mathrm{Bu}_{2} \mathrm{~S}$ vapor to the reaction chamber. The Mo substrates were 25 $\times 75 \mathrm{~mm}^{2}$ in area and placed on to a heated graphite block with injector position $3 \mathrm{~mm}$ above over the upstream region of the substrate. The vapor flow followed a horizontal configuration towards the exhaust. The chamber was kept at atmospheric pressure and the concentration of the precursor vapor was determined by the partial pressure, which was $5.9 \times 10^{-4}$ and $3.7 \times 10^{-3}$ atmospheres for $\mathrm{Et}_{4} \mathrm{Sn}$ and $\mathrm{t}-\mathrm{Bu}_{2} \mathrm{~S}$, respectively. It was necessary to use a 6-fold greater concentration of $t-\mathrm{Bu}_{2} \mathrm{~S}$ to $\mathrm{Et}_{4} \mathrm{Sn}$ due to the higher vapor pressure of sulfur compensating for its re-evaporation from the growing SnS film. The authors have reported [7] these optimised parameters in another article.

A Cirrus portable mass spectrometer was used to sample exhaust gas species after the growth chamber to determine by-products produced from the chemical reaction process after $\mathrm{SnS}$ film formation. Scanning electron microscopy (SEM) and energy dispersive X-ray spectroscopy (EDX) were carried out with a Hitachi TM3000 bench top instrument and used to assess grain size/shape and approximate stoichiometry of the Sn-S deposits. High resolution (HR)-SEM was carried out with a Hitachi S-4800 instrument equipped with field emission gun (FEG) using beam settings at $2-10 \mathrm{keV}$ and $10 \mu \mathrm{A}$. X-ray diffraction (XRD) was used with a Phillips X'PERT MPD instrument to determine the thin film crystal structure.

\section{DISCUSSION}

It was not possible to obtain thin film $\mathrm{SnS}$ when using nitrogen as the carrier gas. This was even the case at chamber temperatures up to $600^{\circ} \mathrm{C}$. Thin film SnS only deposited on to the substrates when using hydrogen as carrier gas and at temperatures greater than $410^{\circ} \mathrm{C}$.

\section{Thermal decomposition of $\mathrm{Et}_{4} \underline{\mathrm{Sn}}$}

The decomposition products of $\mathrm{Et}_{4} \mathrm{Sn}$, from $\mathrm{Et}_{3} \mathrm{Sn}$ to $\mathrm{EtSn}$, with loss of ethyl groups from the precursor, were all detected as soon as $\mathrm{Et}_{4} \mathrm{Sn}$ was injected into the chamber using hydrogen as carrier (Figure 1). On heat up, detected concentrations of these by-products increased, correlating with outgassing of sulfur from parasitic wall deposits within the reactor chamber. At a critical temperature between $410^{\circ} \mathrm{C}$ and $420^{\circ} \mathrm{C}$, $\mathrm{H}_{2} \mathrm{~S}$ was detected. The temperature reached a maximum of $470^{\circ} \mathrm{C}$ with the hydrogen flow 
over the substrate. The carrier gas was then switched from hydrogen to nitrogen, resulting in an immediate drop in all detected exhaust gas by-products, even though the chamber temperature increased towards $600^{\circ} \mathrm{C}$. This gave two observations, the first being that hydrogen was cooling the substrate surface to a certain degree and secondly that the $\mathrm{Et}_{4} \mathrm{Sn}$ thermal decomposition was reliant on hydrogen being used as the carrier gas.

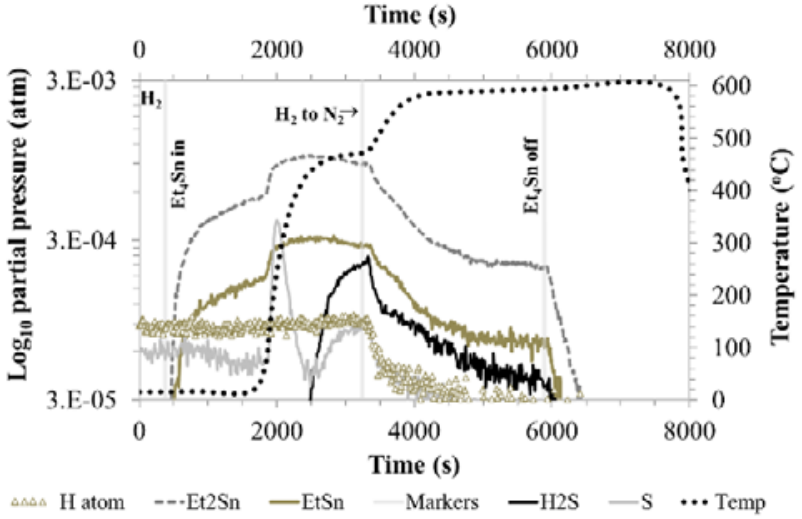

Figure 1. In situ mass spectrum of exhaust gas species after $\mathrm{Et}_{4} \mathrm{Sn}$ precursor injection as a function of time, temperature and type of carrier gas.

\section{Evolution of $\mathrm{H}_{2} \underline{\mathrm{S}}$}

The initial formation of $\mathrm{H}_{2} \mathrm{~S}$ during temperature increase with hydrogen flow is attributed by the sulfur release from parasitic wall deposits. Addition of $t-\mathrm{Bu}_{2} \mathrm{~S}$ results in approximately an order of magnitude increase in the detected partial pressure of $\mathrm{H}_{2} \mathrm{~S}$ (Figure 2). After t-Bu $\mathrm{S}$ injection, the sulfur follows a similar trend to $\mathrm{H}_{2} \mathrm{~S}$, but at lower partial pressures. The $\mathrm{t}-\mathrm{Bu}_{2} \mathrm{~S}$ decomposition products of $\mathrm{t}-\mathrm{Bu}-\mathrm{S}$ and butane were also detected upon $\mathrm{t}-\mathrm{Bu}_{2} \mathrm{~S}$ injection. When $\mathrm{Et}_{4} \mathrm{Sn}$ was then added to the reaction chamber, the detection of both $\mathrm{t}-\mathrm{Bu}-\mathrm{S}$ and butane increased and the butyl group released from $\mathrm{t}-\mathrm{Bu}_{2} \mathrm{~S}$ became detectable, suggesting the $\mathrm{Et}_{4} \mathrm{Sn}$ precursor enhanced $\mathrm{t}-\mathrm{Bu}_{2} \mathrm{~S}$ decomposition. Also at the point of $\mathrm{Et}_{4} \mathrm{Sn}$ injection, some of the $\mathrm{H}_{2} \mathrm{~S}$ and sulfur was observed to be consumed. It was determined that this was due to $\mathrm{SnS}$ being formed at the substrate surface. 


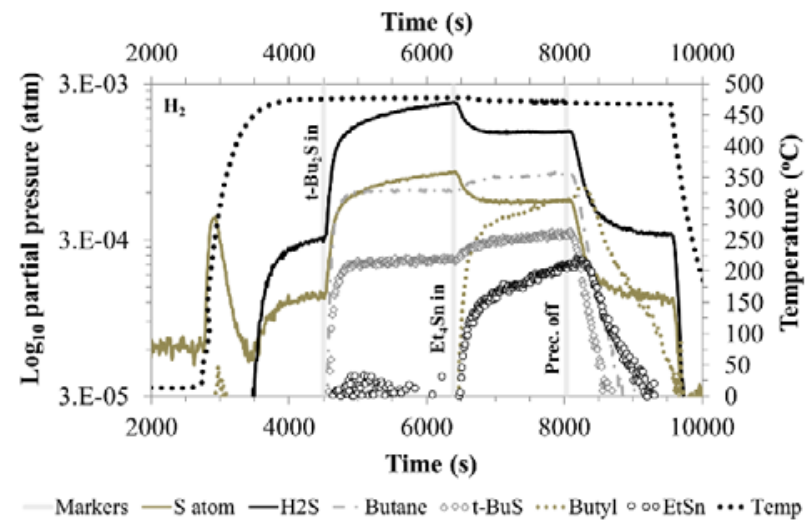

Figure 2. In situ mass spectrum of exhaust gas species after $\mathrm{t}-\mathrm{Bu}_{2} \mathrm{~S}$ injection followed by $\mathrm{Et}_{4} \mathrm{Sn}$ precursor injection as a function of time and temperature.

\section{Thin film sns structural properties}

XRD showed (Figure 3) the film to have no other Sn-S phases present other than $\mathrm{SnS}$. The dominant peak was that of Mo at $2 \theta$ angle of $40.8^{\circ}$. The SnS peaks of the MOCVD-grown thin film correlated with the crystallography open database (COD) patterns for SnS (COD 9008785). There were two preferred orientations in the (101) and (040) planes. A small peak at $2 \theta$ angle of $36.5^{\circ}$ was present from $\mathrm{MoS}_{2}$, which is known to form from the interaction of sulfur with Mo during deposition [8].

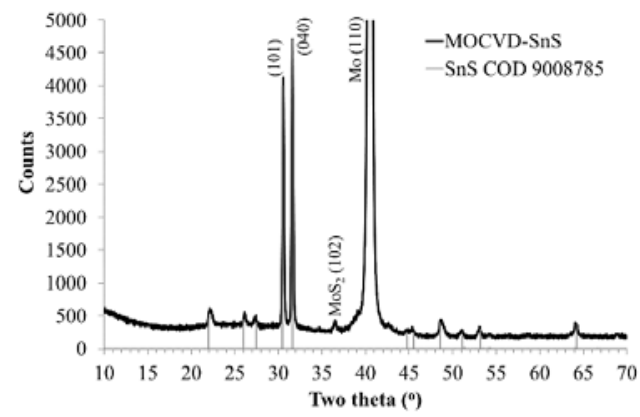

Figure 3. XRD pattern of MOCVD-grown $\mathrm{SnS}$ deposited at $470^{\circ} \mathrm{C}$ on to Mo.

The strong presence of Mo in the XRD pattern suggested the SnS film was thin, or that there was incomplete coverage of the SnS film on the Mo substrate. SEM was carried out on the film to get an indication of grain size (Figure 4). The grains were large, spanning $2 \mu \mathrm{m}$ across and $4 \mu \mathrm{m}$ in length in many cases. However, there were areas of 
significant contrast which were identified as Mo using EDX. This correlated with the strong peak associated with Mo observed in Figure 3. This signified a large vertical growth rate with incomplete coalescence of the grains. Further growth of the SnS should result in coalescence of the films.

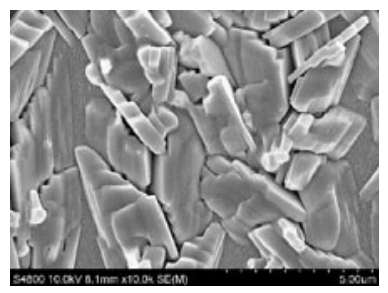

Figure 4. SEM image of MOCVD-grown SnS deposited at $470^{\circ} \mathrm{C}$ on to Mo.

\section{CONCLUSIONS}

XRD determined that single phase thin film SnS was produced using $\mathrm{t}-\mathrm{Bu}_{2} \mathrm{~S}$ as a less toxic sulfur precursor alternative to $\mathrm{H}_{2} \mathrm{~S}$. However, high growth temperatures excessive of $410^{\circ} \mathrm{C}$ were required to produce $\mathrm{SnS}$ with use of hydrogen as carrier gas being essential. This resulted in the formation of $\mathrm{H}_{2} \mathrm{~S}$ within the growth chamber and was determined to be a necessity for $\mathrm{Et}_{4} \mathrm{Sn}$ and its decomposition products to react and form SnS. Large grains were produced using the as-grown process, but vertical growth rate was high leading to incomplete coalescence of the SnS grains, exposing areas of the Mo substrate. Further growth of the $\mathrm{SnS}$ would be expected to lead to coalescence of the grains.

\section{ACKNOWLEDGEMENTS}

The authors would like to acknowledge the European Regional Development Fund (ERDF) and the Welsh European Funding Office (WEFO) for funding the $2^{\text {nd }}$ Solar Photovoltaic Academic Research Consortium (SPARC II) which supported this research. The authors would also like to thank Dr Guillaume Zoppi from Northumbria University for supplying the Molybdenum substrates.

\section{References}

1. M.V. Reddy, G. Sreedevi, P. Chinho, R.W. Miles and K.T.R. Reddy, Curr. Appl. Phys. $15,588(2015)$.

2. C. Candelise, J.F. Speirs and R.J.K. Gross, Renew. Sust. Energy Rev. 15, 4972 (2012).

3. P. Sinsermsuksakul, L. Sun, S.W. Lee, H.H. Park, S.B. Kim, C. Yang and R.G. Gordon, Adv. Energy Mater. 1400496 (2014)

4.
5. S. Siebentritt, Sol. Energy Mater. Sol. Cells, 95, 1471 (2011).
L.A. Burton, Y. Kumagai, A. Walsh and F. Oba, J. Mater. Chem. A, 5,9132 (2017).

6. Z. Jianwen, L. Da and F. Wenxing, Proc. Eng. 26, 1878 (2011).

7. A.J. Clayton, C.M.E. Charbonneau, W.C. Tsoi, P.J. Siderfin and S.J.C. Irvine, Sci. Tech.

Adv. Mater. Accepted for publication, DOI: 10.1080/14686996.2018.1428478.

8. W. Li, J. Chen, H. Cui, F. Liu and X. Hao, Mater. Lett. 134, 87 (2014). 